\title{
The Effect of Imatinib Mesylate for Newly Diagnosed Philadelphia Chromosome-Positive, Chronic-Phase Myeloid Leukemia in Sub-Saharan African Patients: The Experience of Côte d'Ivoire
}

\author{
K. G. Koffi, D. C. Nanho, E. N'dathz, P. Kouehion, R. Dissieka, A. Attia, \\ K. Mozard, A. Tolo, K. Boidy, N. Meité, R. Ayemou, M. Sekongo, N. Tea, and I. Sanogo \\ Haematology National Teaching Hospital of Abidjan, 21 BP 632, Abidjan 21, Cote d'Ivoire \\ Correspondence should be addressed to K. G. Koffi, guskof1@yahoo.fr
}

Received 15 April 2010; Revised 26 May 2010; Accepted 5 July 2010

Academic Editor: Stefan Faderl

Copyright ( $) 2010$ K. G. Koffi et al. This is an open access article distributed under the Creative Commons Attribution License, which permits unrestricted use, distribution, and reproduction in any medium, provided the original work is properly cited.

\begin{abstract}
Imatinib mesylate, showed encouraging activity in chronic myelogenous leukemia. However, there are few data regarding his efficacy and response monitoring in Sub-Saharan African patients. Our objective was to assess response to imatinib mesylate (Glivec) in Côte d'Ivoire patients with newly diagnosed Chronic Myeloid Leukemia (CML). From May 2005 to September 2009, we treated 42 patients ( 40 years; range 16-69) with Philadelphia chromosome $(\mathrm{Ph}+$ ) positive in chronic phase CML with oral imatinib mesylate at daily doses of $400 \mathrm{mg}$. Overall survival (OS) and frequency of complete or major cytogenetic remission (CCR/MCR) were evaluated. At a median follow up of 32 (range 7.6-113) months, the CHR rate in our study group was 76\%. A major CR was found in 19 patients (45\%) with $17 \%$ and $29 \%$ complete and partial CR respectively. There were no significant differences in the incidence of major cytogenetic response by known prognostics factors. Median time to CHR was 8 months (range 0.4-25), and 16 months (range: $0.1-36$ ) for CR. Projected 5-year OS rate was 72\% (95\%CI 42-88). We conclude that imatinib therapy sub-Saharan African CML patients is very promising and has favorably changed the prognosis for black African patients with CML.
\end{abstract}

\section{Introduction}

Chronic myeloid leukemia (CML) is a clonal myeloproliferative disorder of a pluripotent stem cell1 first described by John Hughes Bennett in 1845. It was the first malignancy that had a specific chromosomal abnormality uniquely linked to it after the discovery of a minute chromosome now known as the Philadelphia $(\mathrm{Ph})$ chromosome, later defined to result from a $t(9 ; 22)$ reciprocal chromosomal translocation [1]. Of critical importance was the demonstration that this translocation involved the ABL1 (Abelson) proto-oncogene in chromosome 9 and the $B C R$ (breakpoint cluster region) gene in chromosome 22 [2]. Clinically, CML progresses through three distinct phases: a chronic phase that is easily controlled by conventional chemotherapy followed by an ill-defined unstable accelerated phase, leading to a terminal blastic phase. The latter phase resembles acute leukemia and is highly refractory to chemotherapy with under $20 \%$ response rate and a median survival of 3-6 months [3]. Since then, a constant stream of clinical and basic advances has made CML one of the most extensively studied human malignancies. Imatinib mesylate (STI571, Gleevec; Novartis Pharmaceuticals, East Hanover, NJ) is a selective Bcr-Abl protein tyrosine kinase inhibitor against c$\mathrm{abl}, \mathrm{bcr} / \mathrm{abl}, \mathrm{c}-\mathrm{kit}$, and platelet-derived growth factor receptor (PDGF-R). Imatinib mesylate has demonstrated significant activity in all phases of Philadelphia chromosome- (Ph-) positive chronic myeloid leukemia (CML) [4]. Within the past 5 years, a promising new therapy has become available for the treatment of African patients with CML with the first introduction of Bcr-Abl tyrosine kinase inhibitor imatinib (formerly STI571) into clinical trials. With the availability of free imatinib mesylate in resource-poor countries through donation from the Glivec International Patient-Assistance program (GIPAP); this drug has also become the first-line therapy for CML in Cote d'Ivoire a great relief for patients in resource-limited countries. This paper describes the results for patients with newly diagnosed CML in chronic phase. 


\section{Materials and Methods}

Patients. The national division of Haematology teaching Hospital of Yopougon-Abidjan (CHUY) is the referral centre for diagnosis and treatment of haematology disorders in Côte d'Ivoire. We performed a prospective trial of imatinib mesylate for patients with newly diagnosed African chronic myelogenous leukemia (CML). All patients treated for CML at CHUY have been registered prospectively in our leukemic database, established in 2005. In all patients, the diagnosis of CML was confirmed prior to imatinib mesylate treatment by morphologic review of peripheral blood (PB) and bone marrow and by documentation of the presence of the $B C R$ $A B L$ translocation by conventional metaphase cytogenetic analysis or molecular studies. Chronic phase was defined as fulfilling all the following criteria: (a) peripheral or marrow blasts less than $15 \%$, (b) peripheral or marrow blasts + promyelocytes less than $30 \%$, (c) peripheral or marrow basophils less than $20 \%$, and (d) platelets equal to or greater than $100 \cdot 10^{9} / \mathrm{L}$ [5]. The occurrence of additional karyotypic abnormalities was not considered a criterion for acceleration. The Sokal prognostic score at diagnosis was calculated as described elsewhere [6]. All of the patients gave written informed consent to participate in the studies.

Treatment with Imatinib. In general all patients received imatinib at a oral dose of $400 \mathrm{mg}$ daily; no concomitant chemotherapy was administered other than short courses of hydroxyurea when deemed necessary. Imatinib dosage was adjusted depending on tolerance and response. Imatinib box was delivered to CML patients at the hospital under medical supervision in a full compliance according to GIPAP programs requirements monthly by returning the empty plaques before the next subsidy. Doses were reduced in the presence of grade 3-4 thrombocytopenia or grade 34 neutropenia. Wherever possible the dose was maintained above $300 \mathrm{mg} / \mathrm{day}$. The study was approved by the institutional ethics committee and conducted according to the Declaration of Helsinki. Patients with accelerate and blastic phase were not included in our studies.

Follow-up patients were treated as long as they continued to respond. They were assessed for response to treatment by weekly physical examination, full blood count, and biochemistry for the first 6 -weeks and at 6 week intervals thereafter; bone marrow morphology and cytogenetic were assessed every 3 months. Cytogenetic analysis, using the Gbanding technique, was performed all patients before the initiation of therapy and every 3 months during the course of therapy. Cytogenetic response was determined based on the percentage of $\mathrm{Ph}$-positive metaphases.

2.1. Response Criteria. Cytogenetic responses were classified in accordance with standard UK Medical Research Council practice as complete $(0 \% \mathrm{Ph}+$ metaphases $)$, partial (1-35\% $\mathrm{Ph}+$ metaphases), A major cytogenetic response included complete and partial cytogenetic responses ( $\mathrm{Ph}$-positive less than 35\%), minor (36-95\% $\mathrm{Ph}+$ ) and no response (96-100\% $\mathrm{Ph}+$ ).

End points sustained hematologic and cytogenetic response. Hematologic response was defined as described

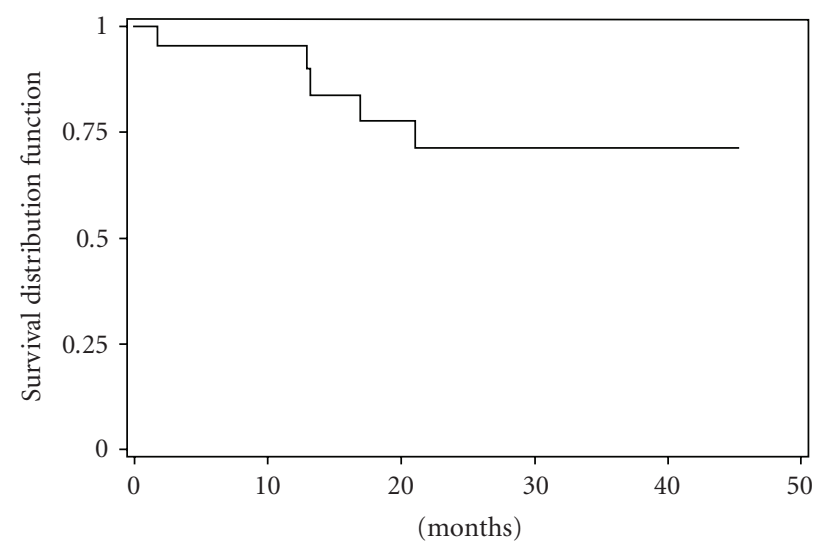

FIgure 1: Overall survival of patients with CML imatinib mesylate therapy.

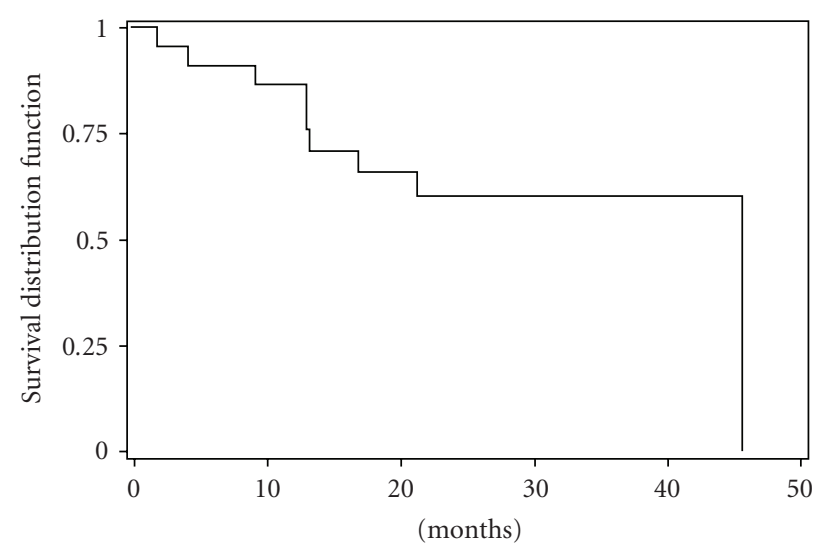

FIGURE 2: Even-free survival of patients with CML imatinib mesylate therapy.

previously. Primary hematologic resistance was considered if patients failed to achieve any hematologic response.

2.2. Adverse Events. Adverse events were graded using the National Cancer Institute/National Institutes of Health Common Toxicity Criteria, Version 2.0. Grade 3/4 hematologic toxicity was assessed regarding the time of first occurrence and duration.

2.3. Statistical Analysis. Survival analysis was performed using the Kaplan-Meier method. Duration of hematologic or MCR was assessed for responding patients as the time from the first observation of response to disease recurrence, death, or last visit. Overall survival was calculated from treatment initiation to death from any cause or at the date of the last visit. Event Free Survival (EFS) was calculated from diagnosis to the first observation of disease progression or death or interrupted treatment for toxicities. For comparison of cohorts, the Mann-Whitney test was employed. 


\section{Results}

Between May 2005 and September 2009, 42 patients with CML were treated with imatinib mesylate (Gleevec).

The clinical characteristics of all patients are shown in Table 1 . The median age of patients was 40 years (range 1669 years), and 26 patients (62\%) were males. The median time from diagnosis was 1.5 years (0.1-7). Risk group (Sokal) stratification for patients with evaluable data was as follows: low risk $16.6 \%$, intermediate risk $44.5 \%$, and high risk $38.9 \%$. Before treatment there were 17 patients (41\%) with additional chromosomal abnormalities (Table 2). The overall median followup time was 32 months (range: 7.6-113 months).

3.1. Response, Duration of Response, and Survival. The median time from diagnosis to start Imatinib was relatively long, 9.41 months (range: 0.2-25 months). Overall rates of hematological and cytogenetic responses to imatinib mesylate therapy are shown in Table 3 . The median followup of the study group was 32 months (range: 7.6-113 months).

The CHR rate in our study group was $76 \%$. A major cytogenetic response was noted in 19 patients $(45 \%)$ : complete in $7(17 \%)$ and partial in $12(29 \%)$. Complete cytogenetic response was achieved in only 1 patient (14\%) 3 months of therapy, in 2 patients (29\%) 6 months, and 4 patients (57\%) 9 months. There were no significant differences in the incidence of major cytogenetic response by known prognostic factors (age, splenomegaly, sex, leukocytosis, thrombocytosis, blasts, and Sokal score). However, during clinical follow-up, patients with additional abnormalities showed significant lower CHR (59\% versus $88 \%)(P=.035)$ and MCyR $(24 \%$ versus $60 \%)(P=.043)$ as compared to those with only $\mathrm{Ph}$ chromosome (Table 4). But there was no significant correlation between CCyR in the two situations. Moreover, there was no significant correlation between cytogenetic and hematologic response and the delay of treatment. The median time to CHR was 8 months (range: 0.4-25 month), and the median time to cytogenetic response was 16 months (range: $0.1-36$ month). The projected 5-year overall survival rate was $72 \%$ (95\%CI: 42-88) (Figure 1). The projected 2-years EFS was $60 \%$ (95\%CI: 35-77\%) (Figure 2). This projected 5 -years overall survival rate by cytogenetic profile was 78\% (95\%CI: 38-94\%) with $\mathrm{Ph}+$ alone versus $62 \%$ (95\%CI; $14-89 \%)$ with $\mathrm{Ph}+$ with additional chromosomal abnormalities. Side effects of imatinib mesylate in this study were similar to those reported previously for the entire imatinib mesylate treatment study. The severe (grade 3-4) toxic effects experienced are shown in Table 5. At a median follow-up duration of at least 32 months (range: 7.6-113 months) Twenty-three (55\%) were alive in chronic phase and are still taking imatinib mesylate, and 10 patients (24\%) died. Eight died after developing blastic phase disease; 2 died from pulmonary tuberculosis associated with accelerated-phase disease. Five patients stopped therapy 3 of cutaneous toxicity, 1 with neurological depression, and 1 with cardiac symptoms. No patients died in chronic phase from imatinib mesylate-related complication. Four patients
TABLe 1: Pretreatment characteristics of the study population of 42 patients with CML.

\begin{tabular}{|c|c|}
\hline Variable & no. \\
\hline \multicolumn{2}{|l|}{ Gender, $n .(\%)$} \\
\hline Male & 26 \\
\hline Female & 16 \\
\hline Age (yrs) (median range) & $40(16-69)$ \\
\hline Time from diagnosis (yr) (median range) & $1.5(0.1-7)$ \\
\hline \multicolumn{2}{|l|}{ ECOG at diagnosis } \\
\hline $0-1$ & $25(59)$ \\
\hline $2-3$ & $17(41)$ \\
\hline Hepatomegaly $n(\%)$ & $15(36)$ \\
\hline \multicolumn{2}{|l|}{ Splenomegaly, $n(\%)$} \\
\hline $0 \mathrm{~cm}$ & $4(10)$ \\
\hline $1-9 \mathrm{~cm} \mathrm{bcma}$ & $25(59)$ \\
\hline$\geq 10 \mathrm{~cm} \mathrm{bcm}$ & $13(31)$ \\
\hline \multicolumn{2}{|l|}{ Peripheral blood (median range) } \\
\hline Hemoglobin level (g/dL) & $10.2(5.7-13.7)$ \\
\hline Platelet count $\left(10^{9} / \mathrm{L}\right)$ & $331.5(132-1992)$ \\
\hline Leukocyte count $\left(10^{9} / \mathrm{L}\right)$ & $211.7(50-854)$ \\
\hline Basophils in $\mathrm{PB}(\%)$ & $0(0-6)$ \\
\hline Blasts in $\mathrm{PB}(\%)$ & $1.9(1-8)$ \\
\hline Blasts in $\mathrm{BM}(\%)$ & $1(0-4)$ \\
\hline \multicolumn{2}{|l|}{$\mathrm{Ph}$ status before therapy, $n(\%)$} \\
\hline $\mathrm{Ph} 1+$ & $25(59)$ \\
\hline Additional chromosomal abnormalities & $17(41)$ \\
\hline \multicolumn{2}{|l|}{ Sokal score } \\
\hline Low risk. $n .(\%)$ & $11(16.6)$ \\
\hline Intermediate risk $n .(\%)$ & $16(44.5)$ \\
\hline High risk $n .(\%)$ & $15(38.9)$ \\
\hline
\end{tabular}

Cma: centimeters below the costal margin.

developed accelerated phase and received dose escalated $600 \mathrm{mg}$ daily of imatinib mesylate.

\section{Discussion}

Our study of patients with newly diagnosed CML chronicphase $\mathrm{Ph}+$ is unique in sub-Saharan Africa. To our knowledge there are few data regarding imatinib therapy for subSaharian African patients with $\mathrm{Ph}+$ leukemia [7]. Regarding the clinical and biological feature, CML of black African patients seems to be generally aggressive. First, the median age of patients with CML in Côte d'Ivoire and other African countries with similar demographic pattern is over 40 years [7-9]. Fleming et al. reported that native African patients less than 40 years suffer from CML more than any other group in the world; the differential age incidence pattern of CML is believed to be due to the age distribution of African population rather than any other inherent biological characteristics [10]. But this age seems to be lower than that reported in Europe and United states [11]. Second, we found, high incidence of additional cytogenetic abnormalities. So 
TABLE 2: Detailed cytogenetic response of $17 \mathrm{CML}$ patients with additional chromosomal abnormalities prior to imatinib therapy.

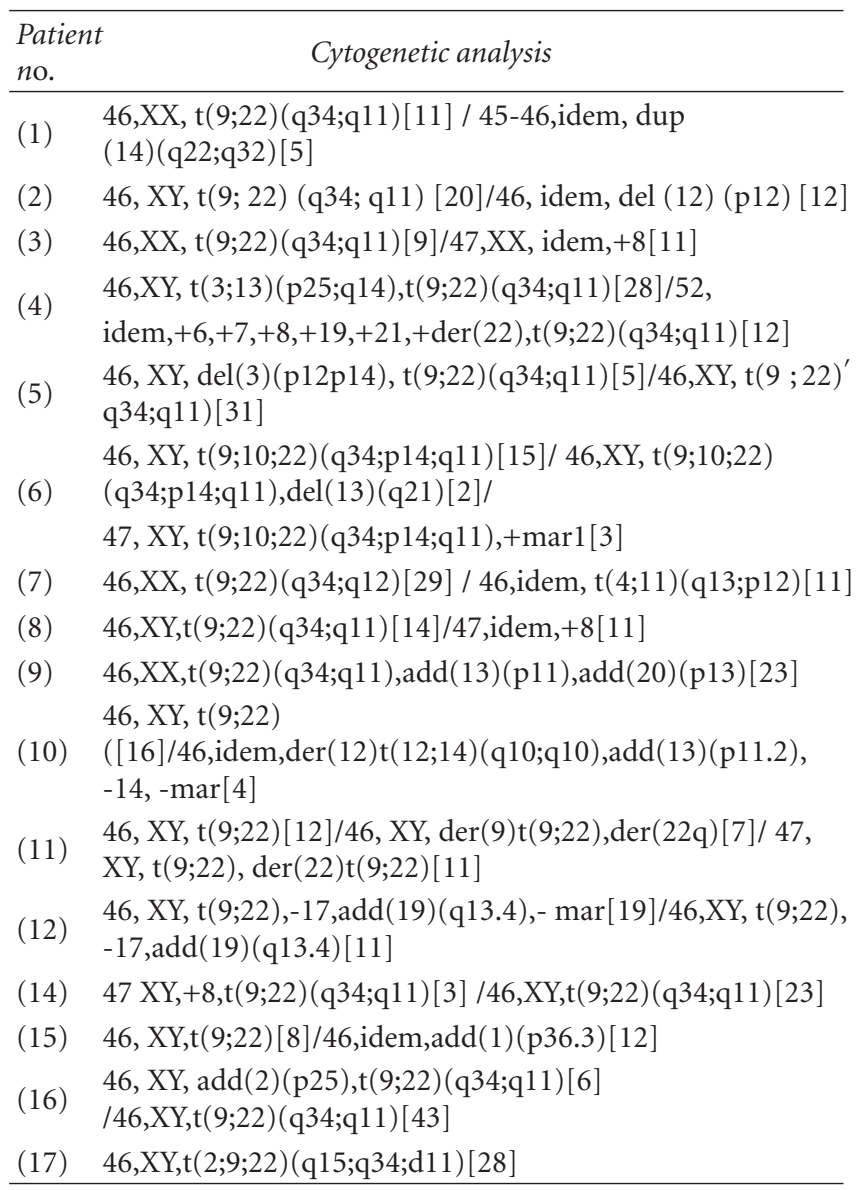

TABLE 3: Hematologic and cytogenetic response.

\begin{tabular}{lc}
\hline Characteristics & $n .(\%)(n=42)$ \\
\hline Hematologic remission & \\
Complete & $32(76)$ \\
Partial & $10(24)$ \\
Cytogenetic response & $33(79)$ \\
Major $(\mathrm{Ph} \leq 35 \%)$ & $19(45)$ \\
Complete $(\mathrm{Ph}+=0 \%)$ & $7(17)$ \\
Partial $(\mathrm{Ph}+=1 \%-35 \%)$ & $12(28)$ \\
Minor $(\mathrm{Ph}+36 \%-95 \%)$ & $14(33)$ \\
Minimal/no $(\mathrm{Ph}+>95 \%)$ & $12(29)$ \\
\hline
\end{tabular}

over $41 \%$ of additional chromosomal abnormalities were found with high incidence of intermediate and high risk of Sokal staging system length in part with the long mean delay from diagnosis 17 months. The high incidence rate of additional chromosomal abnormalities seems particular in African CML leading to the poor prognostic of our patients. In those studies the percentage of additional chromosome abnormalities length was $15 \%$ to $25 \%$ for patients in chronic phase [12-14].

With the overall median follow-up time of 32 months (range: $7.6-113$ months), we found $76 \%$ of $\mathrm{CHR}$ rate and
TABle 4: Hematologic and cytogenetic response according to $\mathrm{Ph}+$ alone or additional chromosomal abnormalities.

\begin{tabular}{lccc}
\hline Characteristics & Ph+alone & $\begin{array}{c}\text { Ph+ with } \\
\text { additional } \\
\text { abnormalities }\end{array}$ & $P$ \\
& $n .(\%)(n=25)$ & $\begin{array}{c}n .(\%) \\
(n=17)\end{array}$ & \\
\hline CHR & $22(88)$ & $10(59)$ & .0357 \\
MCyR & $15(60)$ & $04(24)$ & .043 \\
CCyR & $6(24)$ & $1(6)$ & .210 \\
\hline
\end{tabular}

CHR: complete hematologic response; MCyR: major cytogenetic response; CCY: complete cytogenetic response.

TABLE 5: Incidence of grade 3-4 side effects with imatinib mesylate therapy $(n=42)$.

\begin{tabular}{lc}
\hline Toxicity & $\begin{array}{c}\text { No. }(\%) \text { with grades } \\
3-4 \text { toxicity }\end{array}$ \\
\hline $\begin{array}{l}\text { Non Hematologic toxicities } \\
\text { Bone or Joint aches }\end{array}$ & $11(26)$ \\
Others & (a) \\
Skins rash & $10(24)$ \\
Nausea & $3(7)$ \\
Diarrhea & $2(5)$ \\
Muscle cramps & $2(5)$ \\
Hematologic toxicities & $2(5)$ \\
Granulocytopenia $<1 \cdot 10^{9} /$ liter & $14(33)$ \\
Thrombocytopenia $<50 \cdot 10^{9} /$ liter & $10(24)$ \\
Anemia $<8$ g/d liter & $5(12)$ \\
\hline (a) 2 with fever, 1 with neurological depression symptoms, and 1 with cardiac \\
symptoms, fatigue 6.
\end{tabular}

$79 \%$ had cytogenetic response, which was major in $45 \%$ and complete in only $17 \%$. Thus, the results with imatinib mesylate therapy continue to be positive with longer followup. This result is lower than that of the reported case of literature. The high rate of RCC was reported by Kantarjian et al. and the IRIS study $81 \%$ and $86 \%$,respectively $[15,16]$. The study of Muheez et al. in Nigeria reported 35\% of RCC [7]. But in these several studies patients had previously been treated by INF- $\alpha$ or other chemotherapy as the first-line treatment. Overall, $80 \%$ of newly diagnosed patients with CML in chronic phase would be expected to achieve CCR with imatinib [17].

The median time from diagnosis to commencement of Imatinib was relatively long, t 9.41 months (range: $0.2-25$ months), and it is known that this can worsen the prognosis and reduce the probability of response. Our results suggest that there is a small subset of patients whose leukemic cells remain sensitive to imatinib therapy despite the presence of additional chromosome abnormalities. On the other hand, we observed a larger group of patients (12 of 42 patients, 29\%) who did not attain a CR with STI571 therapy. This result seems to be high compared to those reported in the literature computer $[13,14]$. The karyotype profile of these cases tended to be more complex than the CR cases. 
Follow-up study on the Ph no-responder CML patients revealed that the majority of patients also failed to respond clinically to STI571 or progressed after an initial brief response to therapy. This can be explained by the higher rate of additional cytogenetic chromosome abnormalities. It appears to be a subset of patients with disease that is refractory to a dose of $400 \mathrm{mg} /$ day of imatinib and who may benefit from dose escalation in the first treatmen intent. The results of this case can be improved by frontline therapy with imatinib mesylate in combination with other drugs or by high-dose imatinib mesylate therapy as previously reported by Kantarjian et al. [17].

There were no significant differences in the incidence of major cytogenetic response, by known prognostic factors (age, splenomegaly, sex, leukocytosis, thrombocytosis, blasts,and Sokal systems scoring) perhaps due to the short effectiveness of our study population. In the large randomized study, found the significant correlation between these classical prognostics parameters with the cytogenetic response rate has been $[12,14]$.

Previous experience has led to estimated yearly mortality rates of $10 \%-15 \%$ for patients in chronic-phase CML that had failed to respond or had relapsed during therapy $[18,19]$. In our study our mortality rates were estimated as $24 \%$. This mortality rate seems to be very high.

Imatinib mesylate therapy is now the new standard of care for patients with chronic-phase CML. Combinations of imatinib mesylate with IFN $\alpha$, cytarabine, homoharringtonine, decitabine, or other compounds hopefully will further improve the complete cytogenetic and molecular response rates and thus the long-term prognosis for patients with additional chromosome abnormalities [20].

Nonetheless, the projected 5-years overall survival rate of $72 \%$ (95\%CI, 42-88) seems to be impressive for an African population of patients. The extended IRIS study has recently reported a 5-year overall survival estimated as 89\% [16] and several studies have demonstrated significant survival differences based on the Sokal and/or Hasford risk groups at diagnosis [21-24]. This overall survival in this study was better than that of the reported case of our previous study of alpha-interferon with the projected 5-year overall survival rate of $50 \%$ [25].

Based on this advantage survival, this work has shown that the outcome of imatinib therapy for newly diagnose $\mathrm{Ph}+$ CML chronic phase in the sub-Saharan African country of Côte d'Ivoire is no far different from reports in the Western populations. We conclude that imatinib therapy sub-Saharan African CML patients is very promising despite the high incidence of additional chromosome abnormalities, with the additional advantage of oral availability and tolerability. Imatinib has favorably changed the prognosis for black African patients with CML.

\section{Acknowledgments}

The authors are grateful to Novartis for providing imatinib mesylate (Glivec), the Max Foundation and Axios International for facilitating the delivery of the drug, the National
Hematology Teaching Hospital of Yopougon, Côte d'Ivoire. They are especially grateful to Pasteur Cerba of Paris (France) for cytogenetic analysis.

\section{References}

[1] J. D. Rowley, "A new consistent chromosomal abnormality in chronic myelogenous leukaemia identified by quinacrine fluorescence and Giemsa staining," Nature, vol. 243, no. 5405, pp. 290-293, 1973.

[2] G. Q. Daley, R. A. Van Etten, and D. Baltimore, "Induction of chronic myelogenous leukemia in mice by the P210(bcr/abl) gene of the Philadelphia chromosome," Science, vol. 247, no. 4944, pp. 824-830, 1990.

[3] M. E. O’Dwyer, M. J. Mauro, and B. J. Druker, "Recent advancements in the treatment of chronic myelogenous leukemia," Annual Review of Medicine, vol. 53, pp. 369-381, 2002.

[4] B. J. Druker, M. Talpaz, D. J. Resta et al., "Efficacy and safety of a specific inhibitor of the BCR-ABL tyrosine kinase in chronic myeloid leukemia," New England Journal of Medicine, vol. 344, no. 14, pp. 1031-1037, 2001.

[5] H. M. Kantarjian, D. Dixon, M. J. Keating et al., "Characteristics of accelerated disease in chronic myelogenous leukemia," Cancer, vol. 61, no. 7, pp. 1441-1446, 1988.

[6] J. E. Sokal, M. Baccarani, D. Russo, and S. Tura, "Staging and prognosis in chronic myelogenous leukemia," Seminars in Hematology, vol. 25, no. 1, pp. 49-61, 1988.

[7] A. D. Muheez, O. F. Julius, A. A. Oyekunle, et al., "The use of Imatinib mesylate in Nigerians with chronic myeloid leukemia," Cellular Therapy and Transplantation, vol. 1, no. 2, p. 15, 2008.

[8] P. O. Boma, M. A. Durosinmi, I. A. Adediran, N. O. Akinola, and L. Salawu, "Clinical and prognostic features of Nigerians with chronic myeloid leukemia," The Nigerian postgraduate medical journal, vol. 13, no. 1, pp. 47-52, 2006.

[9] C. C. Okany and O. O. Akinyanju, "Chronic leukaemia: an African experience," Medical Oncology and Tumor Pharmacotherapy, vol. 6, no. 3, pp. 189-194, 1989.

[10] A. F. Fleming and C. Menendez, "Blood," in Principles of Medicine in Africa, E. Parry, R. Godfrey, D. Mabey, and G. Gill, Eds., vol. 78, Cambridge University Press, Cambridge, UK, 2004.

[11] F. D. Groves, M. S. Linet, and S. S. Devesa, "Patterns of occurrence of the leukaemias," European Journal of Cancer Part A, vol. 31, no. 6, pp. 941-949, 1995.

[12] H. Kantarjian, C. Sawyers, A. Hochhaus et al., "Hematologic and cytogenetic responses to imatinib mesylate in chronic myelogenous leukemia," New England Journal of Medicine, vol. 346, no. 9, pp. 645-652, 2002.

[13] J. E. Sokal, G. A. Gomez, M. Baccarani et al., "Prognostic significance of additional cytogenetic abnormalities at diagnosis of Philadelphia chromosome-positive chronic granulocytic leukemia," Blood, vol. 72, no. 1, pp. 294-298, 1988.

[14] H. M. Kantarjian, T. L. Smith, and K. B. McCredie, "Chronic myelogenous leukemia: a multivariate analysis of the associations of patient characteristics and therapy with survival," Blood, vol. 66, no. 6, pp. 1326-1335, 1985.

[15] H. M. Kantarjian, J. E. Cortes, S. O’Brien et al., "Imatinib mesylate therapy in newly diagnosed patients with Philadelphia chromosome-positive chronic myelogenous leukemia: high incidence of early complete and major cytogenetic responses," Blood, vol. 101, no. 1, pp. 97-100, 2003. 
[16] S. G. O'Brien, F. Guilhot, R. A. Larson et al., "Imatinib compared with interferon and low-dose cytarabine for newly diagnosed chronic-phase chronic myeloid leukemia," New England Journal of Medicine, vol. 348, no. 11, pp. 994-1004, 2003.

[17] H. Kantarjian, M. Talpaz, S. O’Brien et al., "High-dose imatinib mesylate therapy in newly diagnosed Philadelphia chromosome-positive chronic phase chronic myeloid leukemia," Blood, vol. 103, no. 8, pp. 2873-2878, 2004.

[18] J. Rodriguez, J. Cortes, T. Smith et al., "Determinants of prognosis in late chronic-phase chronic myelogenous leukemia," Journal of Clinical Oncology, vol. 16, no. 12, pp. 3782-3787, 1998.

[19] S. Sacchi, H. M. Kantarjian, S. O’Brien et al., "Longterm follow-up results of alpha-interferon-based regimens in patients with late chronic phase chronic myelogenous leukemia," Leukemia, vol. 11, no. 10, pp. 1610-1616, 1997.

[20] H. M. Kantarjian, M. Talpaz, S. O’Brien et al., "Imatinib mesylate for Philadelphia chromosome-positive, chronicphase myeloid leukemia after failure of interferon- $\alpha$ : follow-up results," Clinical Cancer Research, vol. 8, no. 7, pp. 2177-2187, 2002.

[21] M. W. N. Deininger and B. J. Druker, "Specific targeted therapy of chronic myelogenous leukemia with imatinib," Pharmacological Reviews, vol. 55, no. 3, pp. 401-423, 2003.

[22] M. E. Gorre, M. Mohammed, K. Ellwood et al., "Clinical resistance to STI-571 cancer therapy caused by BCR-ABL gene mutation or amplification," Science, vol. 293, no. 5531, pp. 876-880, 2001.

[23] J. Hasford, M. Pfirrmann, R. Hehlmann et al., "A new prognostic score for survival of patients with chronic myeloid leukemia treated with interferon alfa," Journal of the National Cancer Institute, vol. 90, no. 11, pp. 850-858, 1998.

[24] J. E. Sokal, E. B. Cox, and M. Baccarani, "Prognostic discrimination in "good-risk" chronic granulocytic leukemia," Blood, vol. 63, no. 4, pp. 789-799, 1984.

[25] A. Tolo-Diebkilé, K. G. Koffi, G. D. Sawadogo, et al., "Therapeutic Impact of $\alpha$ interferon in chronic myelogenous leukemia," Mali Medical, vol. 25, no. 1, pp. 22-27, 2010. 


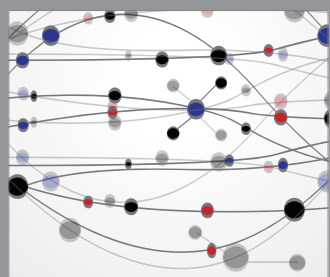

The Scientific World Journal
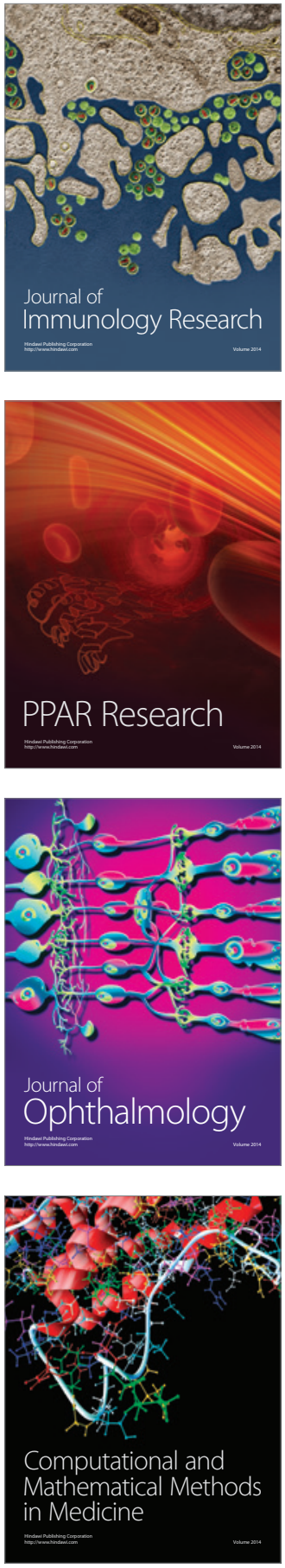

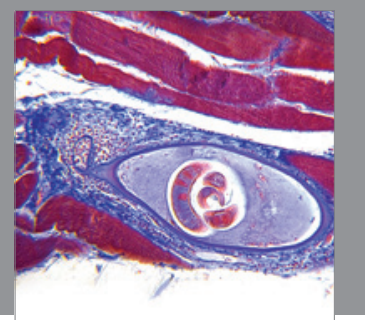

Gastroenterology

Research and Practice
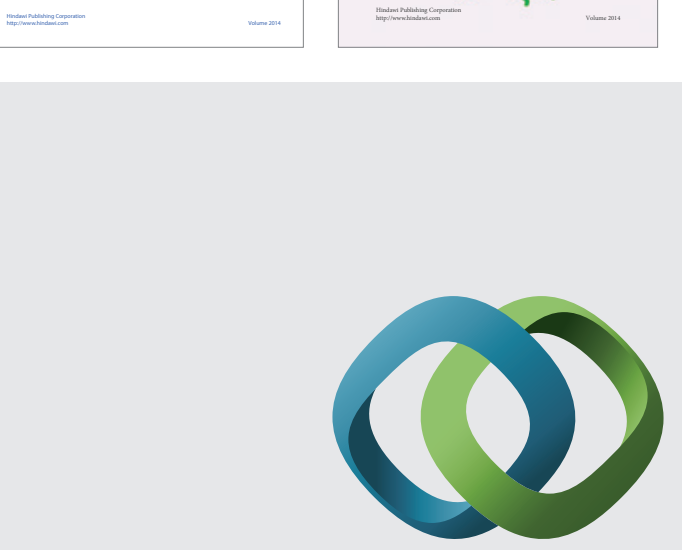

\section{Hindawi}

Submit your manuscripts at

http://www.hindawi.com
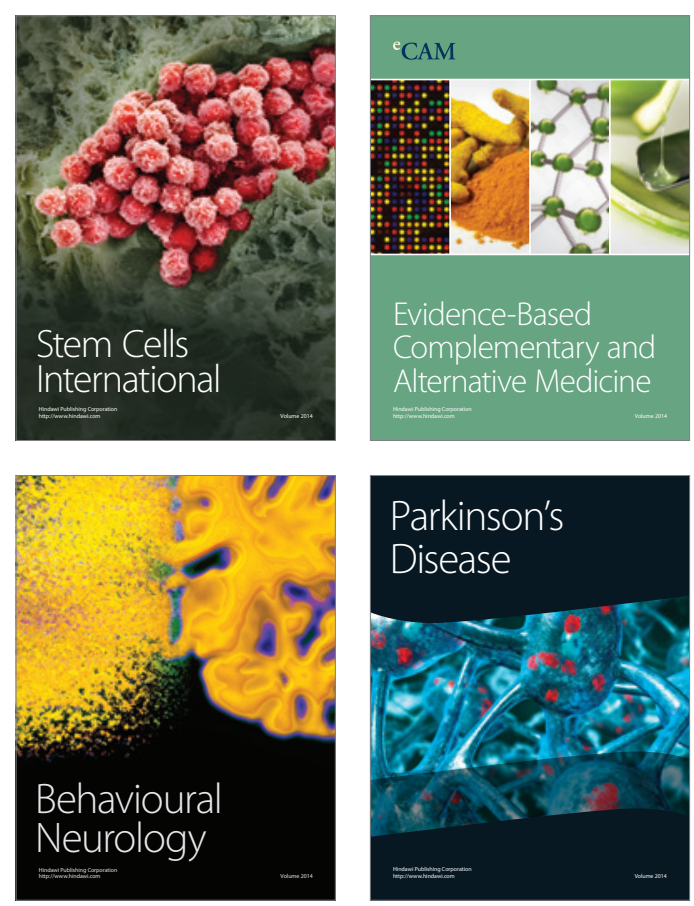

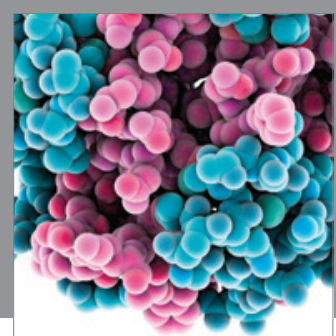

Journal of
Diabetes Research

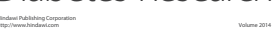

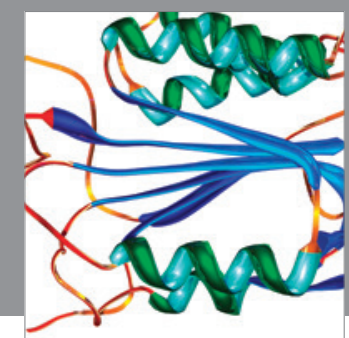

Disease Markers
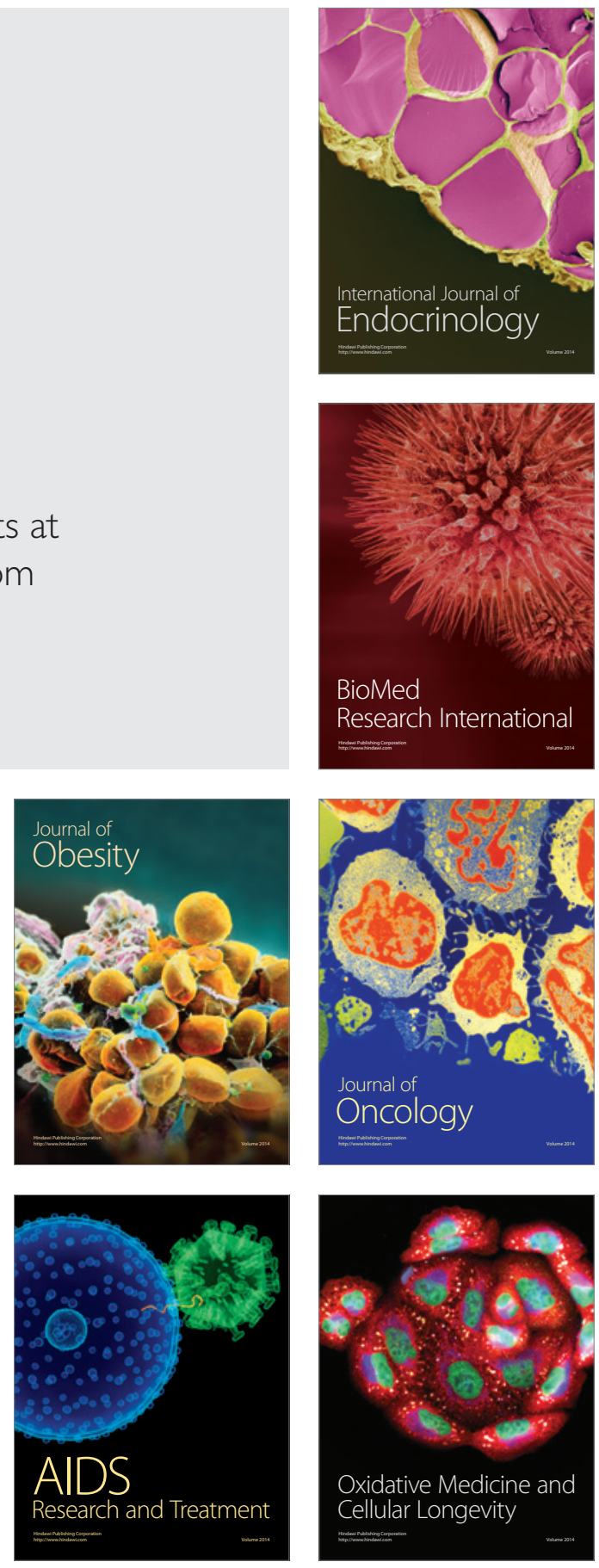